\title{
Analysis on Reasons for Intergenerational Conflicts Between Teachers and Students Under the Core Literacy of Sports and Health and Optimization Path
}

\author{
Min Chen ${ }^{1, *}$ Xiao Chen ${ }^{1}$ Aihua Zhang ${ }^{1}$ Shunbi Mu${ }^{1}$ \\ ${ }^{1}$ Institute of Physical Education, Yunnan Normal University, Kunming, Yunnan 650500, China \\ *Corresponding author.
}

\begin{abstract}
This paper uses literature data method, interview method, and logic analysis method to find out that the conflict between teachers and students in physical education still exists, and explains and analyzes this phenomenon that occurs in physical education in China from the perspective of intergenerational conflict between teachers and students. The causes of inter-generational conflicts between teachers and students in physical education in China's schools are clear. In the context of improving the core literacy of students' physical education and health, inter-generational conflicts between teachers and students will inevitably have a huge impact on the teaching quality of physical education teachers and the learning effects of students. The original teaching effect of the physical education class was greatly reduced, which eventually led to the failure of the core literacy of sports and health of the students, and also indirectly violated China's goal of building a sports power. Therefore, easing and optimizing the conflict between teachers and students in physical education course of China will be an urgent problem to improve the core literacy of students' physical education and health.
\end{abstract}

Keywords: core literacy of sports and health, intergenerational conflict between teachers and students,

analysis of causes, optimization

\section{INTRODUCTION}

In 2017, China promulgated the National Physical Education and Health Curriculum Standards (2017 Edition) of High Schools (hereinafter collectively referred to as the "Curriculum Standards", 2017 Edition"). Its proposal once again pointed out the direction for the development of China's physical education teaching and also set the core literacy of sports and health for students. However, the conflicts between teachers and students on campus occur from time to time. On April 4, 2018, the postgraduate tutor of Wuhan University of Technology Wang Pan and his student Tao Chongyuan entangled in the conflict, and Tao Chongyuan fell from the school building and died [1]. The occurrence of such conflicts not only exists in colleges and universities, but also exists in schools at all levels in China. For China's school physical education course, the occurrence of such conflicts will inevitably lead to the lack of core literacy of sports and health of students, especially the intergenerational conflicts caused by the differences in cognition, concepts and behaviors caused by age between teachers and students cannot be ignored. What are the causes of intergenerational conflicts between teachers and students in school physical education in China, and what measures should the colleges and universities take to avoid and control them? It is worth in-depth exploration.

\section{RESEARCH METHODS}

\section{A. Literature review method}

Through cnki.com, relevant literature was collected with the key words "intergenerational conflicts, teacherstudent conflicts, core literacy of sports and health", and theoretical guarantee was given to the paper.

\section{B. Interview method}

It is required to interview teachers and students in elementary and secondary schools, colleges and universities to understand the current situation of teacher-student relationship and analyze it with the theory of intergenerational conflict.

\section{Logic analysis}

Based on the collected literature, this article extracts the theoretical methods with reference value, combines 
the events that occur, makes judgments and infers solutions based on logical thinking.

\section{INTERPRETATION OF RELATED CONCEPTS}

\section{A. Interpretation on the concept of core literacy of sports and health}

The core literacy of sports and health is the core quality of the subject which is produced under the macro concept of the core quality and has the aim to guide the implementation of physical education and health curriculum. The core literacy of sports and health not only requires knowledge and skills, but also values, character, and abilities that are just as important as knowledge and skills. Therefore, the core literacy of sports and health mainly includes athletic ability, health behavior and sports ethics [2]. (see "Fig. 1").

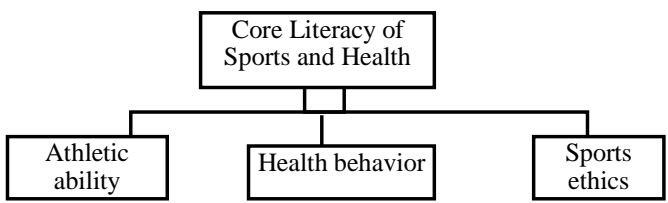

Fig. 1. Construction of core literacy of sports and health.

\section{B. Interpretation of the concept of intergenerational conflict between teachers and students}

The so-called intergenerational conflict between teachers and students means that the "traditional teaching concept" of the teacher and the "new learning concept" of the student are not integrated. This is called the intergenerational conflict between teachers and students.

\section{Causes of intergenerational conflicts between teachers and students in physical education course of China}

1) Cognitive differences: The era in which people grow up is the key to forming the worldview and outlook on life and values. Years of time often determines the way of thinking and the development of life. Today, China's reform and development has entered a new era. The popularity of smartphones below 1,000 yuan and the reduction of network tariffs have sent the Internet to every corner of people's life. For the children of the post-90s, post-00s, and even post-10s, they have become the "original residents" in the era of the Internet. They have been exposed to and learned about the Internet since their birth, making the Internet a part of their lives. Through various channels, they can come into contact with the learning methods with the characteristics of the times, so that they have their own unique views on learning. Therefore, their learning has the characteristics of the times. However, most teachers do not have this "special treatment." They grew up without information-explosive cultural resources, and there were very few ways to obtain cutting-edge knowledge. It mainly relied on traditional teaching and thinking. Therefore, the traditional and solid teaching ideas are deeply entrenched, resulting in a cognitive difference between the teachers and students.

2) Differences in ideas: Affected by the traditional Confucian culture, China has had the concept of "respecting the teacher" since ancient times. That is, in the teaching process, knowledge is important and teachers should be respected. This is not wrong. Due to the over-interpretation by later generations and the education thoughts solidified by China's feudalism for thousands of years, this concept has been deeply rooted in the hearts of the people. Teachers regard themselves as the dominant position in teaching and ignore the subjective initiative of students. Teacher-centered teaching has become the mainstream of school teaching. Although students are also affected by this concept, students are exposed to many new ideas and concepts in the network environment and more easily accept them. However, they are forced to be in a subordinate position under the influence of a strong mainstream culture, forming the "subcultures" [3]. In other words, the intergenerational conflict between teachers and students is also a conflict between two cultures.

3) Behavioral differences: On the one hand, students feel dull and boring about the traditional physical education teaching model, can't find the joy of learning, with depressed mood, negative performance in class, or even violating class discipline. On the other hand, teachers are not satisfied with the performance of students. Coupled with the generation gap", it is difficult to carry out effective communication. The intensification of conflicts and escalations make conflicts unavoidable. Phenomenon of corporal punishment and scolding of students often occur. These behaviors eventually lead to a decline in learning enthusiasm, academic frustration, and teaching enthusiasm. The goal of improving the core literacy of students' physical education is even more difficult to talk about. 


\section{STRATEGIES TO RESOLVE INTERGENERATIONAL CONFLICTS BETWEEN TEACHERS AND STUDENTS IN PHYSICAL EDUCATION OF SCHOOLS}

\section{A. Eliminating differences in cognition of teachers and students}

"Lifelong learning" is an important means for teachers to be at the forefront of education. Times are developing and society is advancing. Every generation of young people will always be branded with the times they belong to, and have the characteristics of the times they grew up in. As Margaret Mead mentioned in "Culture and Commitment," "Even not so long ago, the older generation can reprimand the younger generation without shame: You should understand that you are young but you have never ever been old." However, the younger generation now can rightly answer: "In this world today, I am young, but you have never been younger, and you will never be younger [4]." Therefore, keep learning and follow The pace of the times, proactively understanding the most advanced teaching modes, teaching knowledge, and exploring new teaching methods are important magic weapons for teachers to stay on the front line of teaching for a long time. At the same time, it is required to integrate with students, talk to students, understand students, alleviate conflicts between teachers and students, and lead students to comprehensively improve core literacy of sports and health to achieve educational goals.

\section{B. Reducing differences in perceptions of teachers and students}

As an excellent physical education teacher, it is required to have excellent sports skills and profound physical education knowledge. At the same time, it is necessary to have a passionate love of students. Tao Xingzhi, a well-known educator in China, once said, "Here is a heart, not leave with half a grass." Physical education teachers should truly love their students. They must put down the fixed thought of teachercentered, abandon the shackles of traditional ideas, and be willing to go among students and listen to their inner thoughts, and listen to students' suggestions with an open mind. In combination with the professional knowledge of physical education, it is necessary to formulate the teaching content, choose the appropriate teaching methods, establish the teaching concept that students are the subject of learning, and ensure the scientific nature of physical education classroom teaching. At the same time, it is necessary to integrate with students, be a guide on their way to study, be a good friend in life, and become a true mentor to students.

\section{Avoiding differences in behavior of teacher and student}

"Teacher is the most glorious profession in the sun." This famous saying from the famous educator Comenius is not only outdated, but it deserves everyone's attention. With the concept of "rejuvenating the country through science and education, and health first", physical education teachers teach students a large amount of sports knowledge and skills. They are both the guide for student learning and the booster for students' physical and mental health. However, this does not completely explain the value of physical education teachers. He must also undertake the cultivation of student moral education. Therefore, when facing a sudden situation in the classroom, the physical education teacher should calm down, analyze the cause of the incident, find the main contradiction, and then deal with humorous or "moderate" means. The teachers can't have conflicts with students or scold them. Under appropriate circumstances, the role of teachers and students can be changed to allow students to take turns as a teacher, so that they can experience the hard work of the teacher, so as to draw closer to each other and understand each other. On the one hand, students can experience the teachers' hard work firsthand and recognize the mistakes they make, and then better maintain the order in the classroom without violating classroom discipline. On the other hand, the teacher not only handles the problems properly, but also wins the respect of the students. This is of great help to carry out the work in the future.

\section{CONClusion}

In short, times are changing and society is advancing. Today, with the overall improvement of core qualities in sports and health, the conflict between teachers and students is the biggest stumbling block. Intergenerational conflicts are important factors that cannot be ignored. It not only affects the relationship between teachers and students, but also hinders the healthy and happy development of students. "Curriculum Standards (2017 Edition)" has been released, and a new era of teaching is coming. Behind it, there are also huge challenges for teachers, students and the general public. It is necessary to take it lightly. The teachers must work up the minds and actively face the unknown challenges. This article has made immature opinions. Much of what has not been studied should be further developed.

\section{References}

[1] Frequent conflicts and scandals between teachers and students in universities directly reflect the abnormal teacher-student relationship [EB / OL]. //news.iqilu.com/meitituijian/20180409/3880378.shtml 
[2] Ji Liu. Interpretation of National Physical Education and Health Curriculum Standards (2017 Edition) of High Schools in China [J]. Sports Science, 2018 (2): 5. (in Chinese)

[3] Shi Zhongying. Intergenerational conflicts and the transformation of modern teacher roles [J]. Journal of Modern Education, 1997 (1): 15-16. (in Chinese)

[4] Margaret Mead. Culture and Commitment: A Study on the Generation Gap Problem [M]. Translated by Zhou Xiaohong, Shijiazhuang: Hebei People's Publishing House, 1987: 7. (in Chinese)

[5] Fu Xiao. Investigation and Analysis of the Causes of teacherstudent conflict [J]. Education and Management,2004(34):4244. (in Chinese)

[6] Wu Xiaoying. Intergenerational conflict and the Change of Youth Discourse [J]. Youth Research,2006(08):1-8. (in Chinese)

[7] Yu Xiaohui. Building harmonious Social Relations with Cultural Identity [J]. Academic Exploration,2018(09):134-139. (in Chinese) 